\title{
Clinical examination factors that predict delayed recovery in individuals with concussion
}

\author{
Corina Martinez ${ }^{1 *}$ D, Zachary Christopherson ${ }^{1}$, Ashley Lake ${ }^{1}$, Heather Myers ${ }^{1}$, Jeffrey R. Bytomski²,
} Robert J. Butler ${ }^{3,4}$ and Chad E. Cook ${ }^{4}$

\begin{abstract}
Background: Risk factors for prolonged recovery after concussion have been well researched, but specific objective clinical examination findings have not. This study examined whether clinical examination results could predict delayed recovery (DR) in individuals with concussion diagnosis. A secondary aim explored the influence of early examination on individual prognosis.

Methods: The study was a retrospective, observational cohort design that included 163 individuals seen at a concussion clinic who were followed longitudinally until cleared for sports activity. Cognitive, visual, balance, vestibular, and cervical clinical testing and symptom assessment were performed at initial evaluation. DR was calculated by taking the median value associated with time to clearance for activity. Bivariate logistic regression analysis was calculated to determine odds ratios (and 95\% confidence intervals) for the odds of DR with presence or absence of each clinical finding. Multivariate analyses were used to define the best predictors of DR.

Results: 80 of 163 individuals were considered delayed in their clearance to activity. Cognitive impairments (OR $=2.72$; $95 \% \mathrm{Cl}=1.40,5.28)$, visual exam findings $(\mathrm{OR}=2.98 ; 95 \% \mathrm{Cl}=1.31,6.80)$, and vestibular exam findings $(\mathrm{OR}=4.28$; $95 \% \mathrm{Cl}=2.18,8.43)$ all increased the odds of a DR. Multivariate modeling retained cognitive symptoms and clinical examination-vestibular testing as predictors of delayed recovery. Time to examination after injury was a mediator for DR.

Conclusions: The clinical examination provides value in identifying individuals who are likely to exhibit a delayed clearance. In particular, vestibular impairments identified clinically at initial evaluation and cognitive symptoms were associated with increased odds of a DR to return to activity. Our data support that early implementation of a standardized clinical examination can help to identify individuals who may be more at risk of prolonged recovery from concussion.
\end{abstract}

Keywords: Concussion, Post-concussion syndrome, Vestibular

\footnotetext{
* Correspondence: corina.martinez@duke.edu

'Department of Physical Therapy and Occupational Therapy, Duke University, DUMC 3965, Durham, NC 27705, USA

Full list of author information is available at the end of the article
}

(c) The Author(s). 2020 Open Access This article is licensed under a Creative Commons Attribution 4.0 International License, which permits use, sharing, adaptation, distribution and reproduction in any medium or format, as long as you give appropriate credit to the original author(s) and the source, provide a link to the Creative Commons licence, and indicate if changes were made. The images or other third party material in this article are included in the article's Creative Commons licence, unless indicated otherwise in a credit line to the material. If material is not included in the article's Creative Commons licence and your intended use is not permitted by statutory regulation or exceeds the permitted use, you will need to obtain permission directly from the copyright holder. To view a copy of this licence, visit http://creativecommons.org/licenses/by/4.0/. The Creative Commons Public Domain Dedication waiver (http://creativecommons.org/publicdomain/zero/1.0/) applies to the data made available in this article, unless otherwise stated in a credit line to the data. 


\section{Background}

The incidence of sports-related concussion (SRC) in high school and collegiate athletes is reported to be 0.11 and 0.28 , respectively, per 1000 athlete-exposures, a number that has steadily risen over the last decade [1]. This accounts for an estimated 1.6 to 3.8 million concussions annually [2] and equates to approximately $5 \%$ of the total number of injuries across different sports with American football, girls' soccer, boys' soccer, and girls' basketball resulting in the majority of concussion in high school athletes [1]. Of these nearly 4 million concussions, around 300,000 involve youth athletes aged 14-19 [3], with visits to the emergency department for pediatric sports-related traumatic brain injuries increasing $60 \%$ over the previous 10 years [4].

The majority of individuals who suffer from sportsrelated concussion fully recover within a few days to several weeks [5]. However, there is a portion of the population who experience symptoms beyond the generally accepted time frame for recovery. Recovery is interpreted as resolution of symptoms and clearance to return to sport activity. This condition is commonly referred to as post-concussion syndrome (PCS), a term used to describe the presence of nonspecific signs and symptoms that are linked to several possible causes that do not necessarily reflect ongoing physiological brain injury [6]. There is a paucity in the literature regarding the time frame for PCS. Williams et al. found that high school athletes tend to report longer symptom recovery than college athletes [3]. A recent 4-year study following NCAA athletes found that most symptoms associated with concussion resolved within 1 week (60.1\%); however, $6.2 \%$ had a resolution of symptoms of over 4 weeks, and $8.9 \%$ of concussions required over 4 weeks before return to play [2].

A multitude of risk factors for developing PCS have been identified in the literature including severity of initial symptoms, prolonged headache, subjective concentration deficits, female gender, referral to a concussion rehabilitation program, history of prior concussion, dizziness, vestibulo-ocular dysfunction and younger age [715]. Others have also reported history of psychological (e.g. depression, anxiety) or neurodevelopmental (e.g. attention-deficit/hyperactivity disorder [ADHD], learning disability [LD]) disorders as risk factors for developing PCS [2, 4, 16-18]. Most of the research related to determining which athletes will have a resolution of symptoms has been focused on correlations to performance on computerized neuro-cognitive/neuropsychological testing and formal sideline testing [5, 17-20], with little attention paid to the relationship between PCS and clinical examination findings.

The clinical examination used to assess concussion is variable based on the preferences and experiences of the clinician because there are no established guidelines on required components. In general, it will consist of the following: a detailed history, neurological examination, cognitive examination including neurocognitive screening, cervical spine screening, balance testing, vestibularocular motor screening, and some form of reaction time testing [21, 22]. Prognostic information regarding risk factors is important because it allows clinicians to be more confident in management decisions regarding return to play and gives perspective regarding the potential for delayed recovery. However, little is known about the correlation between clinical examination findings and prolonged recovery.

The timing of former clinical examination following a concussive injury is another factor that has not been well researched. Diagnosis of concussion is typically made acutely by licensed athletic trainers, team physicians, emergency department providers, or urgent care providers using commonly accepted sideline concussion diagnostic tools such as the Sideline Concussion Assessment Tool or the King-Devick Test [23, 24]. Following the acute concussion diagnosis, referral to a licensed healthcare provider is consistently recommended, however the optimal timing for clinical follow-up is not established.

The aim of this study was to examine whether clinical examination results could predict delayed recovery in individuals with concussion symptoms who were seen acutely at a concussion clinic. A secondary aim was to explore the role of early examination and how this influences the prognosis of the individual.

\section{Methods}

\section{Reporting guidelines}

The study used the STrengthening the Reporting of OBservational studies in Epidemiology (STROBE) guidelines for reporting of cohort studies. STROBE is endorsed by a growing number of biomedical journals and aims to improve reporting standards of observational studies [25].

\section{Study design}

The study was a retrospective, observational cohort design that evaluated subjects after exposure to a clinically diagnosed concussion based on mechanism of injury, symptom report, and clinical presentation as defined by the international consensus statement on concussion in sport [23]. Follow-up data were captured at a number of time-points including baseline (post-exposure), followup and discharge. The study protocol (ID Pro00058398) was approved by the institutional review board at the medical center where the study was conducted.

\section{Setting}

All data were captured at a sports concussion clinic that operates within the Duke Sports Sciences Institute 
(DSSI). The DSSI is a multidisciplinary facility with medical and rehabilitation management options for sports related injury and non-injury management. The concussion clinic is staffed by four primary care sports medicine physicians trained in concussion management. All individuals with concussion were evaluated by one of these physicians and clinical decision making was based on established protocols supported by the literature. The evaluation required the individual to complete subjective questionnaires including the Post-Concussion Symptom Scale, The Neck Disability Index, and the Dizziness Handicap Index. The clinical examination was comprised of standardized concussion tests including the Standardized Assessment of Concussion (SAC) for cognitive assessment, King-Devick Test for visual assessment, Vestibular-Ocular Motor Screen (VOMS) for visual (smooth pursuit and convergence) and vestibular (saccades, VOR, VMS) assessment, and the Balance Error Scoring System (BESS) for balance assessment. Cervical testing was considered positive if neck pain was present at rest, with palpation, or with active motion. Standard clinical concussion care was provided to all individuals based on their initial presentation.

\section{Participants}

Participants included 163 adolescent and college aged individuals who self-presented or were referred for evaluation at the sports concussion clinic at the Duke Sports Sciences Institute between July 1, 2013 and January 1,2015. Eligibility required a medical diagnosis of sports-related concussion and the willingness to receive a battery of questionnaires, examinations, and follow up. Follow up occurred through January 22, 2015 as indicated by standard of care.

\section{Variables}

Descriptive characteristics included age, sex, Neck Disability Index score (NDI), Dizziness Handicap Index score (DHI), Post-Concussion Symptom Scale (PCSS), and time from concussion incident to clinical examination. The NDI is a 10-item questionnaire that identifies the presence of neck pain with daily activities such as personal care, reading, lifting, driving, sleeping, and work and is scored as a percentage disability [26]. The DHI asks the subject to rate self-perceived dizziness or imbalance difficulties during 25 daily activities which may be impacted by vestibular involvement [27]. The PostConcussion Symptom Scale is a subjective rating of the severity of 22 common post-concussive symptoms scored on a 7 point (Likert) scale with the maximum value being 132 . The PCSS is a commonly used selfassessment rating of concussion symptoms that has been shown to be predictive of concussive injuries. The symptoms on the PCSS can be categorized into 4 domains which include physical, cognitive, emotional, and sleep disturbances [28, 29].

Predictor variables included the presence or absence of 1) headache, 2) dizziness, 3) neck pain, 4) cognitive impairments, 5) photophobia, 6) phonophobia, and 7) vision disturbances as a primary symptom. The above variables were determined by subjective history taken at the beginning of the evaluation and were considered positive if individual endorsed presence of the symptom during the acute phase of the concussion. Predictors also included a series of standard clinical examinations for cognitive testing, cervical screening, visual testing, balance testing, and vestibular testing (Table 1). Clinical examination data were calculated as 'positive' or 'negative'. An additional predictor was "time to examination",

Table 1 Clinical examination tests utilized at initial evaluation

\begin{tabular}{|c|c|c|c|}
\hline System & Assessment Method & $\begin{array}{l}\text { Abnormal } \\
\text { Findings }\end{array}$ & Reference \\
\hline Cognitive & Standardized Assessment of Concussion (SAC) & $\begin{array}{l}\text { Score }<26 \text {, mean } \\
\text { score } 26.6 \text { (1996 } \\
\text { McCrea) }\end{array}$ & $\begin{array}{l}\text { McCrea M, Kelly J, Randolph C. Standardized Assessment } \\
\text { of Concussion (SAC): Manual for Administration, Scoring } \\
\text { and Interpretation. Waukesha, WI: CNS Inc.; } 1996 .\end{array}$ \\
\hline Cervical & $\begin{array}{l}\text { Active ROM } \\
\text { Palpation of spinous processes and musculature }\end{array}$ & $\begin{array}{l}\text { Pain } \\
\text { Decreased ROM }\end{array}$ & \\
\hline Visual & King-Devick (KD) & $\begin{array}{l}\text { Symptom } \\
\text { provocation } \\
\text { during test }\end{array}$ & $\begin{array}{l}\text { Galetta KM, Barrett J, Allen M, et al. The King-Devick test as } \\
\text { a determinant of head trauma and concussion in boxers } \\
\text { and MMA fighters. Neurology. } 2011 ; 76 \text { (17):1456-1462. doi: } \\
\text { https://doi.org/10.1212/WNL.0b013e31821184c9. }\end{array}$ \\
\hline Balance & Balance Error Scoring System (BESS) & $\begin{array}{l}\text { Score }>19 \\
\text { normal scores } \\
12.03 \pm 7.34\end{array}$ & $\begin{array}{l}\text { Guskiewicz KM. Postural stability assessment following } \\
\text { concussion: One piece of the puzzle. Clin J of Sport Med. } \\
\text { 2001;11 (3):182-189. }\end{array}$ \\
\hline Vestibular & $\begin{array}{l}\text { Vestibular Oculomotor Screen (VOMS): } \\
\text { (1) smooth pursuit, (2) horizontal and vertical saccades*, } \\
\text { (3) near point of convergence (NPC) distance, (4) } \\
\text { horizontal vestibular ocular reflex (VOR)*, and (5) visual } \\
\text { motion sensitivity (VMS) } \\
{ }^{*} \text { Performed for } 10 \mathrm{~s}\end{array}$ & $\begin{array}{l}\text { Symptom } \\
\text { provocation with } \\
\text { any of the tests }\end{array}$ & $\begin{array}{l}\text { Mucha A, Collins MW, Elbin RJ, et al. A Brief Vestibular/ } \\
\text { Ocular Motor Screening (VOMS) Assessment to Evaluate } \\
\text { Concussions: Preliminary Findings. Am J Sports Med. 2014; } \\
\text { 42:2479-2486. }\end{array}$ \\
\hline
\end{tabular}


which was the difference between the first examination date and the original injury date. Time to examination was dichotomized by median values to improve the understanding of the analyses and to examine the necessity of a sub-classification of time to examination.

The outcome variable for this study was time to clearance. Time to clearance was calculated by subtracting the numbers of days from the date of clearance by the date of examination. The resulting value was in 'days'. Time to clearance was dichotomized by median values to improve the understanding of the analyses and to create odds ratios for each predictor variable. Those with days above the median were defined as "delayed recovery" whereas those with days below the median were defined as "non-delayed recovery".

\section{Bias}

To decrease risk of bias the statistician was different than the clinicians and database stewards of the study.

\section{Study size}

For simple univariate multinomial or logistic regression, Homer and Lemeshow have recommended a minimum observation-to-variable ratio of 10:1, but cautioned that a number this low will likely overfit a model [30]. Their preferred observation-to-variable ratio is $20: 1$ for the multivariate modeling, thus an appropriate number for multivariate modeling would range 120 to 240 if all predictor variables were eligible for the final analysis [30].

\section{Statistical methods}

All analyses were performed using SPSS version 20.0 (IBM Corp. Armonk, NY, USA). Subject characteristics, including means, standard deviations, and frequencies were reported for age, gender, disability, dizziness, symptom statuses and time to examination. Descriptive characteristics were reported in raw values. All patient report data were categorized as present or absent.

Univariate logistic regression analyses were performed for each of the predictor variables using the outcome variable of time to clearance. Nuisance variables for history of concussion, LD/ADHD and migraines were included in each regression. Logistic regression analysis was used because the pass rates were not normally distributed, could not be appropriately log-transformed, and failed to meet the assumptions of a linear regression analysis. For each univariate analysis, individual $P$-values, odds ratios (ORs) and 95\% confidence intervals (CIs), were reported.

Associations in the univariate analyses with $\mathrm{P}$-values $\leq 0.05$ were considered in a distinct hierarchical multivariate predictive model which included the full sample. After assessment of collinearity, multivariate analyses (backwards stepwise regression) were used to define the best predictors of delayed recovery. Secondary analyses included multivariate modeling for two subgroups: 1) delayed time to examination and 2) early time to examination, to determine the influence of examination timing on predictive outcomes.

\section{Availability of data and materials}

The datasets analyzed during the current study are not publicly available due to institutional restrictions regarding the accessibility of private health information. A limited dataset, with HIPAA identifiers removed, may be available from the corresponding author on reasonable request.

\section{Results \\ Participants}

The sample was mostly younger (mean age $=16.2 \mathrm{SD}=$ 3.63) males (65\%), who most frequently were seen after a direct hit to the head (55.3\%) and most commonly included American football players (33.1\%). The mean time from injury to examination in days was $10.4(\mathrm{SD}=$ $27.2)$, range 0 to 256 days $(\mathrm{Q} 1=2$; $\operatorname{med}=4 ; \mathrm{Q} 3=7.5)$. The mean time from injury to clearance (in days) was $29.63(\mathrm{SD}=97.93)$, range $0-422$ days $(\mathrm{Q} 1=4 ; \operatorname{med}=9$; $\mathrm{Q} 3=20$ ). The study included 163 individuals who were initially seen for their concussion in the 2014 calendar year and tracked until full resolution of their concussion symptoms. Eighty (80) were considered delayed in their clearance to activity taking 29 days or more to recover from their concussion. Those with delayed clearance to activity also had longer days between injury and examination (Table 2).

\section{Main results}

Univariate analyses identified statistically significant relationships between headache $(\mathrm{OR}=3.53 ; 95 \% \mathrm{CI}=1.08$, 11.47), dizziness $(\mathrm{OR}=2.14 ; 95 \% \mathrm{CI}=1.13,4.02)$, cognitive impairments $(\mathrm{OR}=2.72 ; 95 \% \mathrm{CI}=1.40,5.28)$, clinical examination-cognitive testing $(\mathrm{OR}=3.52 ; 95 \% \mathrm{CI}=1.08$, 11.48), clinical examination-visual testing $(\mathrm{OR}=2.98$; $95 \% \mathrm{CI}=1.31,6.80$ ), and clinical examination-vestibular testing $(\mathrm{OR}=4.28$; $95 \% \mathrm{CI}=2.18,8.43)$ and delayed return to activity. In all conditions, presence of these symptoms or test findings at initial clinical testing was associated with delayed clearance to activity (Table 3).

Multivariate hierarchical modeling identified the statistically significant relationships between cognitive symptoms $(\mathrm{OR}=2.78 ; \quad 95 \% \mathrm{CI}=1.29, \quad 5.97)$ and clinical examination-vestibular testing $(\mathrm{OR}=3.19 ; 95 \% \mathrm{CI}=1.49$, 6.82) and delayed clearance to activity. In both cases, presence of these findings at initial evaluation was associated with delayed clearance to activity (Table 4). 
Table 2 Descriptive characteristics of the sample $(N=163)$

\begin{tabular}{llll}
\hline Variables & $\begin{array}{l}\text { Total } \\
\text { Sample }\end{array}$ & $\begin{array}{l}\text { Individuals with a Delayed } \\
\text { Recovery and Clearance }\end{array}$ & $\begin{array}{l}\text { Individuals with a Non-Delayed } \\
\text { Recovery and Clearance }\end{array}$ \\
\hline Gender & $\begin{array}{l}57=\text { female } \\
106=\text { male }\end{array}$ & $\begin{array}{l}34=\text { Female } \\
46=\text { Male }\end{array}$ & $\begin{array}{l}23=\text { Female } \\
60=\text { Male }\end{array}$ \\
Age & $16.25(3.63)$ & $16.47(4.36)$ & $16.02(2.81)$ \\
Neck Disability Index Score (\%) & $21.65(17.81)$ & $21.80(14.30)$ & $21.21(26.23)$ \\
Dizziness Handicap Inventory Score (\%) & $29.62(19.65)$ & $30.47(17.97)$ & $28.00(25.70)$ \\
Total Number of Symptoms (out of 22) & $7.13(7.06)$ & $9.57(7.38)$ & $4.70(5.88)$ \\
Time from Injury to Examination (days) & $10.40(27.16)$ & $17.10(37.43)$ & $4.07(6.43)$
\end{tabular}

\section{Secondary analyses}

Sub-analyses of individuals with fewer days from injury to examination yielded three statistically significant findings in the multivariate modeling. A significant relationship was found between cognitive symptoms $(\mathrm{OR}=4.90$; $95 \% \mathrm{CI}=1.44,16.64)$, clinical examination-vision $(\mathrm{OR}=$ $4.54 ; 95 \% \mathrm{CI}=1.18,17.71)$ and clinical examinationvestibular testing $(\mathrm{OR}=4.49 ; 95 \% \mathrm{CI}=1.34,15.03)$ and delayed clearance to activity (Table 5 ). There were no significant relationships in the sub-analysis of individuals with longer days from injury to examination (Table 6).

\section{Discussion}

The objective of this study was to examine whether clinical examination results were associated with clearance to return to activity in individuals with concussion symptoms who were seen acutely at a concussion clinic. A secondary aim was to explore the role of early

Table 3 Relationship between self-reported clinical symptoms and clinical examination findings and likelihood of delayed outcome $^{a}$

\begin{tabular}{lll}
\hline Variable (symptom) & $\begin{array}{l}\text { Odd Ratio } \\
(95 \% \text { confidence Interval) }\end{array}$ & $\begin{array}{l}\boldsymbol{P} \\
\text { value }\end{array}$ \\
\hline Headache & $3.53(1.08,11.47)$ & $\mathbf{0 . 0 4}$ \\
Dizziness & $2.14(1.13,4.02)$ & $\mathbf{0 . 0 2}$ \\
Neck Pain & $0.99(0.47,2.01)$ & 0.93 \\
Cognitive impairments & $2.72(1.40,5.28)$ & $<\mathbf{0 . 0 1}$ \\
Photophobia & $1.10(0.54,2.21)$ & 0.79 \\
Phonophobia & $1.38(0.64,2.98)$ & 0.40 \\
Vision & $0.98(0.45,2.13)$ & 0.96 \\
Clinical Examination - Cognitive & $3.52(1.08,11.48)$ & $\mathbf{0 . 0 4}$ \\
testing & & $<\mathbf{0 . 0 1}$ \\
Clinical Examination - Visual testing & $2.98(1.31,6.80)$ & 0.10 \\
Clinical Examination - Balance & $2.04(0.86,4.81)$ & \\
testing & & $\mathbf{0 . 0 1}$ \\
Clinical Examination - Vestibular & $4.28(2.18,8.43)$ & 0.23 \\
testing & & \\
Clinical Examination - Cervical & $2.03(0.95,4.34)$ & \\
testing & & \\
a Control for history of concussion, LD/ADHD, and Migraines $(\mathbf{N = 1 6 3 )}$ &
\end{tabular}

examination and how this influences the prognosis of the individual. Of the 163 individuals with concussion, 154 (94.4\%) were 18 and under. Our data support that the use of selected clinical examination findings to capture specific clinical symptoms can identify the likelihood of a delayed recovery. Further, the strength of these associations appears to be mediated by fewer days between injury and clinical examination.

Symptoms of headache, dizziness, and self-reported cognitive impairments were associated with delayed recovery in the bivariate analysis, whereas only cognitive symptoms were statistically significant in the multivariate findings. Multivariate analysis of sub-sample of patients who had fewer days from injury to examination also found cognitive symptoms to predict delayed recovery. Others have identified the role of cognitive symptoms on delayed recovery $[8,31]$. Brown conducted a prospective cohort study of patients who presented to a Sports Concussion Clinic within 3 weeks of injury and found from the variables assessed that total symptom burden at initial visit and cognitive activity level were independently associated with duration of symptoms [32]. Lau et al. reported that presence of on-field dizziness was associated with an odds ratio of 6.34 of protracted recovery after concussion [5]. This study associated acute dizziness with a 2.11 odds ratio of protracted recovery, but also found that headache and cognitive

Table 4 Multivariate analysis of relationship between selfreported clinical symptoms, clinical examination findings, and delayed outcome likelihood ${ }^{\mathrm{a}}$

\begin{tabular}{lll}
\hline Variable (symptom) & $\begin{array}{l}\text { Odd Ratio }(95 \% \text { confidence } \\
\text { Interval) }\end{array}$ & $\begin{array}{l}P \\
\text { value }\end{array}$ \\
\hline Headache Symptoms & $1.60(0.43,5.99)$ & 0.48 \\
Dizziness Symptoms & $1.87(0.87,4.04)$ & 0.11 \\
Cognitive Symptoms & $2.78(1.29,5.97)$ & $\mathbf{0 . 0 1}$ \\
Clinical Examination - & $1.68(0.43,6.53)$ & 0.45 \\
Cognitive & & 0.23 \\
Clinical Examination - Vision & $1.77(0.70,4.47)$ & $<\mathbf{0 . 0 1}$ \\
Clinical Examination - & $3.19(1.49,6.82)$ & \\
Vestibular & & \\
${ }^{a}$ Control for history of concussion, LD/ADHD, and Migraines $(N=163)$ &
\end{tabular}


Table 5 Multivariate analysis of sub-sample of patients who had fewer days from injury to examination ${ }^{a}$

\begin{tabular}{lll}
\hline Variable (symptom) & $\begin{array}{l}\text { Odd Ratio }(95 \% \text { confidence } \\
\text { Interval) }\end{array}$ & $\begin{array}{l}P \\
\text { value }\end{array}$ \\
\hline Headache Symptoms & $1.35(0.12,14.38)$ & 0.80 \\
Dizziness Symptoms & $1.74(0.54,5.62)$ & 0.35 \\
Cognitive Symptoms & $4.90(1.44,16.64)$ & $\mathbf{0 . 0 1}$ \\
$\begin{array}{l}\text { Clinical Examination - } \\
\text { Cognitive }\end{array}$ & $1.26(0.19,8.23)$ & 0.81 \\
Clinical Examination - Vision & $4.54(1.18,17.51)$ & $\mathbf{0 . 0 3}$ \\
$\begin{array}{l}\text { Clinical Examination - } \\
\text { Vestibular }\end{array}$ & $4.49(1.34,15.03)$ & $\mathbf{0 . 0 2}$ \\
$\begin{array}{l}\text { analyzing the relationship between report of clinical symptoms and clinical } \\
\text { examination findings and the likelihood of a delayed outcome }(N=86)\end{array}$
\end{tabular}

impairments had increased likelihood of delayed clearance with odds ratios of 3.48 and 3.65 respectively.

The clinical examination findings during cognitive testing, visual testing, and vestibular testing were associated with delayed recovery in the bivariate analysis, whereas only vestibular symptoms were statistically significant in the multivariate findings. Visual and vestibular examination findings were both statistically significant in the sub-analyses involving early examination after injury. Few others have studied the relationship between visual symptoms and delayed recovery. Heitger et al. compared 36 patients at 3-5 months with post concussive syndrome following a mild closed head injury to a cohort with normal recovery and found the post concussive syndrome group performed worse on antisaccades, self-paced saccades, memory-guided sequences and smooth pursuit [33]. Maruta et al. looked at the presence of cognitive deficits in adults with persistent symptoms after a concussion and found they demonstrated increased gaze position error variability on visual tracking following an attention demanding task [34]. There is also paucity in the literature looking at the

Table 6 Multivariate analysis of sub-sample of patients who had extended (longer) days from injury to examination ${ }^{\text {a }}$

\begin{tabular}{lll}
\hline Variable (symptom) & $\begin{array}{l}\text { Odd Ratio }(95 \% \text { confidence } \\
\text { Interval) }\end{array}$ & $\begin{array}{l}P \\
\text { value }\end{array}$ \\
\hline Headache Symptoms & $0.74(0.09,5.58)$ & 0.77 \\
Dizziness Symptoms & $2.41(0.73,7.93)$ & 0.15 \\
Cognitive Symptoms & $1.86(0.61,5.84)$ & 0.27 \\
Clinical Examination - & $3.40(0.31,36.96)$ & 0.32 \\
Cognitive & & \\
Clinical Examination - Vision & $0.65(0.16,2.63)$ & 0.54 \\
Clinical Examination - & $3.11(0.91,10.68)$ & 0.07 \\
Vestibular & &
\end{tabular}

${ }^{a}$ Analyzing the relationship between report of clinical symptoms and clinical examination findings and the likelihood of a delayed outcome $(N=77)$ relationship between vestibular symptoms as predictors of delayed recovery follow concussion [35]. Zhou and Brodsky conducted a case series chart review of 42 pediatric patients with balance and/or vestibular complaints following sports-related concussions and found that $90 \%$ of the children with protracted dizziness or imbalance following sports-related concussion had at least one abnormal finding with the most frequent deficit found in dynamic visual acuity testing [36].

Current literature has looked at the role of timing in concussion management specific to removal from play and incidence of delayed recovery, but there are no reports of how time to clinical evaluation is associated with delayed recovery. Asken et al. conducted a crosssectional study of 97 athletes who sustained a sportrelated concussion and grouped them into immediate removal from activity or delayed removal from activity and found athletes in the latter group averaged 4.9 more days missed than those is the immediate removal group [37]. With respect to prognosis, the current findings support the importance of early examination after injury in mitigating a delayed recovery.

The current authors found that early examination had a mediating effect on the predictors and outcome variables. Interestingly, there were no predictors in the sample of patients who were involved in a later examination that were associated with delayed recovery. Past findings of studies that have failed to identify predictors may have been influenced by the sample of the patients and whether the individuals were seen earlier versus later following injury.

\section{Limitations}

The study design as a retrospective analysis is one limitation. For this study, delayed recovery was associated with time to clearance. Delayed recovery was defined as individuals who took longer than the median value of time to clearance and not a clinically defined time point such as 14 days. To increase the understanding of the analysis, time to clearance was categorized by median values. Timing to clearance is a variable that is notably influenced by outside factors; factors that may not be related to the symptoms of the patient such as 1) physician variability, 2) access to care, 3) the nature of the activity that is needed for clearance, 4) psychosocial components related to return to school/sport. Further, the study used multiple providers which could influence the interpretation of clinical exams and consistency of performance of exams. Lastly, there may be consistency issues when reporting the presence of acute symptoms as the reliability of the report depends on the person completing the forms as well as the length of time from injury to evaluation. 


\section{Conclusions}

Selected symptoms and a standardized clinical examination provide value in identifying individuals who are likely to exhibit a delayed recovery. In particular, a positive finding during vestibular testing and presence of cognitive impairments identified at initial evaluation were associated with increased odds of a delayed clearance to return to activity. Our data also support the mediating influence of time to examination. Prognosis of delayed recovery may have greater utility when symptoms are captured and tests are performed early after onset of injury.

\section{Acknowledgements}

The authors would like to acknowledge the physicians and physical therapists of the Duke Sports Concussion Clinic for their clinical expertise in the management of concussion injuries.

\section{Authors' contributions}

CM assisted with the conception and design of the study, performed data acquisition and was a major contributor in writing the manuscript. ZC was a major contributor in writing the manuscript. AL contributed to multiple revisions of the manuscript during the writing process. HM provided research support for the design of the study and was critical in obtaining IRB approval for the study. JB contributed to the conception, interpretation, and revision of the manuscript. RB and CC analysed and interpreted the data. All authors read and approved the final manuscript.

\section{Funding}

This study was performed without the assistance from any funding sources or grants.

\section{Availability of data and materials}

The datasets analysed during the current study are not publicly available due to institutional restrictions regarding the accessibility of private health information. A limited dataset, with HIPAA identifiers removed, may be available from the corresponding author on reasonable request.

\section{Ethics approval and consent to participate}

The study was a retrospective, observational cohort design that evaluated subjects after exposure to a medically diagnosed concussion. The study was approved by the Duke University institutional review board. Due to the retrospective nature of the study, consent to participate was not obtained.

\section{Consent for publication}

Not applicable.

\section{Competing interests}

Dr. Chad Cook is an editor for well-known research journals. Additionally, Dr. Cook receives paid royalties for his published videos and books. The results of this study do not constitute endorsement by the ACSM. The authors declare that the results of this study are presented clearly, honestly, and without fabrication, falsification, or inappropriate data manipulation. The remaining authors declare no competing interests.

\section{Author details \\ 'Department of Physical Therapy and Occupational Therapy, Duke University, DUMC 3965, Durham, NC 27705, USA. ²Department of Orthopedics, Duke University, Durham, NC, USA. ${ }^{3}$ St Louis Cardinals, St. Louis, MO, USA. ${ }^{4}$ Division of Physical Therapy, Department of Orthopedics, Duke University, 2200 W. Main Street, Durham, NC 27708, USA}

Received: 11 June 2019 Accepted: 8 May 2020

Published online: 26 May 2020

\section{References}

1. Daneshvar DH, Nowinski CJ, McKee AC, Cantu RC. The epidemiology of sport-related concussion. Clin Sports Med. 2011;30(1):1-17.
2. Wasserman EB, Kerr ZY, Zuckerman SL, Covassin T. Epidemiology of sportsrelated concussions in National Collegiate Athletic Association athletes from 2009-2010 to 2013-2014: symptom prevalence, symptom resolution time, and return-to-play time. Am J Sports Med. 2016;44(1):226-33.

3. Williams RM, Puetz TW, Giza CC, Broglio SP. Concussion recovery time among high school and collegiate athletes: a systematic review and metaanalysis. Sports Med. 2015;45(6):893-903.

4. Thomas DG, Apps JN, Hoffmann RG, McCrea M, Hammeke T. Benefits of strict rest after acute concussion: a randomized controlled trial. Pediatrics. 2015;135(2):213-23.

5. Lau BC, Collins MW, Lovell MR. Sensitivity and specificity of subacute computerized neurocognitive testing and symptom evaluation in predicting outcomes after sports-related concussion. Am J Sports Med. 2011;39(8): 1209-16.

6. Leddy JJ, Baker JG, Willer B. Active rehabilitation of concussion and postconcussion syndrome. Phys Med Rehabil Clin N Am. 2016 May 31;27(2):437-54

7. Bock S, Grim R, Barron TF, et al. Factors associated with delayed recovery in athletes with concussion treated at a pediatric neurology concussion clinic. Childs Nerv Syst. 2015;31(11):2111-6.

8. Corbin-Berrigan LA, Gagnon I. Postconcussion symptoms as a marker of delayed recovery in children and youth who recently sustained a concussion: a brief report. Clin J Sport Med. 2017;27(3):325-7.

9. Ellis MJ, Cordingley D, Vis S, Reimer K, Leiter J, Russell K. Vestibulo-ocular dysfunction in pediatric sports-related concussion. J Neurosurg Pediatr. 2015;16(3):248-55.

10. Field M, Collins MW, Lovell MR, Maroon J. Does age play a role in recovery from sports-related concussion? A comparison of high school and collegiate athletes. J Pediatr. 2003;142(5):546-53.

11. Guskiewicz KM, McCrea M, Marshall SW, et al. Cumulative effects associated with recurrent concussion in collegiate football players: the NCAA concussion study. JAMA. 2003;290(19):2549-55.

12. Howell DR, Mannix RC, Quinn B, Taylor JA, Tan CO, Meehan WP 3rd. Physical activity level and symptom duration are not associated after concussion. Am J Sports Med. 2016:44(4):1040-6.

13. Lau BC, Kontos AP, Collins MW, Mucha A, Lovell MR. Which on-field signs/ symptoms predict protracted recovery from sport-related concussion among high school football players? Am J Sports Med. 2011;39(11):2311-8.

14. Makdissi M, Darby D, Maruff P, Ugoni A, Brukner P, McCrory PR. Natural history of concussion in sport: markers of severity and implications for management. Am J Sports Med. 2010;38(3):464-71.

15. Silverberg ND, Gardner AJ, Brubacher JR, Panenka WJ, Li JJ, Iverson GL. Systematic review of multivariable prognostic models for mild traumatic brain injury. J Neurotrauma. 2015;32(8):517-26.

16. Meares S, Shores EA, Taylor AJ, et al. The prospective course of postconcussion syndrome: the role of mild traumatic brain injury. Neuropsychology. 2011;25(4):454-65.

17. Miller JH, Gill C, Kuhn EN, et al. Predictors of delayed recovery following pediatric sports-related concussion: a case-control study. J Neurosurg Pediatr. 2016;17:491-6.

18. Waljas M, Iverson GL, Lange RT, et al. A prospective biopsychosocial study of the persistent post-concussion symptoms following mild traumatic brain injury. J Neurotrauma. 2015;32(8):534-47.

19. Erlanger D, Saliba E, Barth J. Almquist J, Webright W, Freeman J. Monitoring resolution of Postconcussion symptoms in athletes: preliminary results of a web-based neuropsychological test protocol. J of Athl Train. 2001;36(3):280-7.

20. Iverson G. Predicting slow recovery from sport-related concussion: the new simple-complex distinction. Clin J Sport Med. 2007;17(1):31-7.

21. Pellman EJ, Lovell MR, Viano DC, Casson IR. Concussion in professional football: recovery of NFL and high school athletes assessed by computerized neuropsychological testing - part 12. Neurosurgery. 2006;58(2):263-74.

22. Matuszak JM, McVige J, McPherson J, Willer B, Leddy J. A practical concussion physical examination toolbox: evidence-based physical examination for concussion. Sports Health. 2016;8(3):260-9.

23. McCrory $\mathrm{P}$, Meeuwisse $\mathrm{WH}$, Aubry $\mathrm{M}$, et al. Consensus statement on concussion in sport: the 4th international conference on concussion in sport, Zurich, November 2012. J Athl Train. 2013;48(4):554-75.

24. Zuckerbraun NS, Atabaki S, Collins MW, Thomas D, Gioia GA. Use of modified acute concussion evaluation tools in the emergency department. Pediatrics. 2014;133(4):635-42.

25. von Elm E, Altman DG, Egger M, Pocock SJ, Gotzsche PC, Vandenbroucke JP. The Strengthening the reporting of observational studies in 
epidemiology (STROBE) statement: guidelines for reporting observational studies. Ann Intern Med. 2007;147(8):573-7.

26. Macdermid JC, Walton DM, Avery S, et al. Measurement properties of the neck disability index: a systematic review. J Orthop Sports Phys. 2009:39(5): 400-C12.

27. Jacobson GP, Newman CW. The development of the dizziness handicap inventory. Arch Otolaryngol-Head Neck Surg. 1990;116(4):424-7.

28. Lovell MR, Iverson GL, Collins MW, et al. Measurement of symptoms following sports-related concussion: reliability and normative data for the post-concussion scale. Appl Neuropsychol. 2006;13(3):166-74.

29. Pardini D, Stump J, Lovell M, Collins M, Moritz K, Fu F. The post concussion symptom scale (PCSS): a factor analysis [abstract]. Br J Sports Med. 2004; 38(5):661-2.

30. Hosmer DW, Lemeshow S. Applied logistic regression. 2nd ed. New York: Wiley; 2000. p. 392

31. Eisenberg MA, Meehan WP 3rd, Mannix R. Duration and course of postconcussive symptoms. Pediatrics. 2014;133(6):999-1006.

32. Brown NJ, Mannix RC, O'Brien MJ, Gostine D, Collins MW, Meehan WP. Effect of cognitive activity level on duration of post-concussion symptoms. Pediatrics. 2014;133(2):299-304.

33. Heitger MH, Jones RD, Macleod AD, Snell DL, Frampton CM, Anderson TJ. Impaired eye movements in post-concussion syndrome indicate suboptimal brain function beyond the influence of depression, malingering or intellectual ability. Brain. 2009;132:2850-70.

34. Maruta J, Spielman LA, Yarusi BB, Wang Y, Silver JM, Ghajar J. Chronic postconcussion neurocognitive deficits. II. Relationship with persistent symptoms. Front Hum Neurosci. 2016;10(45):1-10.

35. Hoffer ME, Gottshall KR, Moore R, Balough BJ, Wester D. Characterizing and treating dizziness after mild head trauma. Otol Neurotol. 2004;25(2):135-8.

36. Zhou G, Brodsky JR. Objective vestibular testing of children with dizziness and balance complaints following sports-related concussions. Otolaryngol Head Neck Surg. 2015;152(6):1133-9.

37. Asken BM, McCrea MA, Clugston JR, Snyder AR, Houck ZM, Bauer RM. "playing through it": delayed reporting and removal from athletic activity after concussion predicts prolonged recovery. J Athl Train. 2016;51(4):329-35.

\section{Publisher's Note}

Springer Nature remains neutral with regard to jurisdictional claims in published maps and institutional affiliations.

Ready to submit your research? Choose BMC and benefit from:

- fast, convenient online submission

- thorough peer review by experienced researchers in your field

- rapid publication on acceptance

- support for research data, including large and complex data types

- gold Open Access which fosters wider collaboration and increased citations

- maximum visibility for your research: over $100 \mathrm{M}$ website views per year

At BMC, research is always in progress.

Learn more biomedcentral.com/submissions 